and financed, in addition to improved access to mental health services, the human rights of people who are mentally unwell could be safeguarded to a greater extent by the new act when it comes into power.

\section{References}

Antony, J. (2014) Mental Health Care Bill 2013: a disaster in the offing? Indian Journal of Psychiatry, 56(1), 3-7.

Bhaumik, S. (2013) Mental health bill is set to decriminalise suicide in India. BMJ, 347, f5349.

Chanpattana, W., Kunigiri, G., Kramer, B. A., et al (2005) Survey of the practice of electroconvulsive therapy in teaching hospitals in India. Journal of ECT, 21, 253-254.

Dhandha A. (2010) Status Paper on the Rights of Persons Living with Mental Illness in Light of the UNCRPD. In Harmonizing Laws with UNCRPD. Report prepared by the Centre of Disability Studies. Human Rights Law Network.
Gangadhar, B. N. (2013) Mental Health Care Bill and electroconvulsive therapy: anesthetic modification. Indian Journal of Psychological Medicine, 35, 225-226.

Gopikumar, V. \& Parasuraman, S. (2013) Mental illness, care and the bill: a simplistic interpretation. Economic and Political Weekly, 48(9), 69-73.

Kala, A. (2013) Time to face new realities: Mental Health Care Bill, 2013. Indian Journal of Psychiatry, 55, 216-219.

Narayan, C. L., Narayan, M. \& Shikha, D. (2011) The ongoing process of amendments in MHA-87 and PWD Act-95 and thei implications on mental health care. Indian Journal of Psychiatry, 53 , 343-350.

Somasundaram, O. (1987) The background of Indian Lunacy Act, 1912. Indian Journal of Psychiatry, 29, 3-14.

Trivedi, J. K. (2002) The mental health legislation: an ongoing debate. Indian Journal of Psychiatry, 44, 95-96.

World Health Organization (2005) Mental Health Atlas. WHO.
MENTAL HEALTHLAW PROFILE

\title{
Mental health law in Pakistan
}

\author{
Amina Tareen ${ }^{1}$ and Khalida Ijaz Tareen ${ }^{2}$
}

${ }^{1}$ Consultant Child and Adolescent Psychiatrist, Barnet, Enfield and Haringey Mental Health NHS Trust, UK, email aminatareen@ gmail.com

2Professor Emeritus, King Edward Medical University, Lahore, Pakistan; Co-Chairperson, Tareen Mental Health Foundation; Past President of the Pakistan Psychiatric Society, 1999-2001 We would like to thank Professor Syed Haroon Ahmed for information and advice provided.
Continued efforts to produce appropriate mental health legislation in Pakistan led to the Mental Health Ordinance of 2001. However, with the 18th amendment to the constitution and devolution of health responsibilities to the provincial governments, it became the task of the provinces to pass appropriate mental health legislation through their respective assemblies. Currently the mental health legislative picture is fragmented and unsatisfactory. Only the provinces of Sindh and Punjab have a mental health act in place and there is an urgent need for similar legislative frameworks in other provinces to protect the rights of those with mental illness.

\section{Background}

When Pakistan was created by the division of the Indian subcontinent in 1947, the newly created state continued with the Lunacy Act of 1912, which had been in place in British India. The focus of the act was more on detention than on treatment and with advances in treatment, especially the introduction of psychotropic medication, updated legislation was needed. In the 1970s and onwards, advocates for reform of this legislation were active. The government of Pakistan proposed a new mental health act in 1992 and circulated a draft among psychiatrists for their comments (Rehman, 1994) but it was not until 2001 that the Lunacy Act of 1912 was replaced by the Mental Health
Ordinance of 2001. A draft document was presented at the biennial conference of the Pakistan Psychiatric Society in Islamabad in 2001, attended by a number of UK psychiatrists, who, together with Pakistani psychiatrists, further shaped the draft. A large number of psychiatrists from Pakistan have been trained in the UK and the UK currently has a large number of British Pakistani psychiatrists who maintain strong links with psychiatry in Pakistan. Unsurprisingly, therefore, given these historical and ongoing links, the ordinance had significant similarities to the UK's Mental Health Act 1983.

The Mental Health Ordinance 2001 was in the form of a presidential order and set out to

'amend the law relating to the treatment and care of mentally disordered persons, to make better provision for their care, treatment, management of properties and affairs and to encourage community care and further to provide for promotion of mental health and prevention of mental disorder.' (Government of Pakistan, 2001)

The ordinance dealt with access to mental healthcare and voluntary and involuntary treatment. The duration of involuntary admission varied under different clauses. For instance, detention for assessment was for 28 days, detention for treatment was for 6 months, detention for the purposes of urgent admission was for up to 72 hours and emergency holding of a patient already in hospital could last 24 hours. The ordinance outlined processes by which patients had a right of appeal against their involuntary admission, which would be heard by the local magistrate, with applications made within 14 days of detention. Patients 
could also be discharged to the care of their relatives at any stage of their treatment once they had recovered adequately. The patient's relatives had protected rights to get the patient discharged.

The ordinance limited the period of forced detention by police and magistrates to a maximum of 72 hours. Prior to this it was 10 days, extendable to 30 days with a magistrate's order, which was of course prone to abuse.

Sections of the ordinance dealt with competency, capacity and guardianship issues for people with mental illness. Chapter 7 addressed the protection of human rights, including confidentiality and informed consent. Chapter 8 dealt with offences against persons with a mental disorder, including: wilfully making false statements so as to discredit someone as having a mental disorder; wilful neglect by a manager of the estate of a patient or refusal to deliver that patient's accounts or property; ill treatment or neglect of a patient by the staff of a psychiatric facility; and inhumane treatment or exploitation. This was an attempt to deal with common abuses. However, there was a gap insofar as there was no clarity about how offences committed by a person with a mental disorder were dealt with, leaving this to be dealt with by other sections of criminal and civil law (Gilani et al, 2005).

Under this ordinance, the Federal Mental Health Authority was established with the aim of developing national standards of care of patients, as well as setting a code of practice to be followed by all those involved with the care of patients under this ordinance. A Board of Visitors was constituted to provide regular inspections and review of facilities to ensure that they were in proper order.

However, despite these advances in the legislative framework, unsurprisingly, practice lagged behind. The Federal Mental Health Authority, which was formed in 2001, lapsed without achieving any significant progress in the implementation of the ordinance. Similarly, by 2010 the Board of Visitors of the provinces had not yet come into existence (Mufti, 2010). As the ordinance was not passed by an act of parliament into law, it lapsed.

\section{Current situation: provincial reform}

Following the 18th amendment in the constitution of Pakistan, health was made a provincial subject rather than a federal one. On 8 April 2010, the Federal Mental Health Authority was dissolved and responsibilities were devolved to the provinces, and it became their task to pass appropriate mental health legislation through their respective assemblies.

So far, only the province of Sindh has made significant progress. Lobbyists within Sindh proposed some changes to the Mental Health Ordinance of 2001 (Pakistan Association for Mental Health, 2002). They argued that respect for human rights must inspire the whole text of a law on mental health rather than a single chapter. Thus the Mental Health Authority and Board of Visitors include a retired judge of the High Court of Sindh.
Article 54 of the ordinance specifically speaks of a 'mentally disordered' accused person detained in jail being seen by the Inspector General of Prisons to ascertain his or her state of mind. Provisions should be made to divert an offender with a mental disorder from the criminal justice system to the mental health system. There is a need to establish forensic psychiatric services where such offenders are treated. Section 53(3) refers to the provision of an assessment by the Board or two of its members to ascertain a person's state of mind, where a person is detained for 'offences affecting the public health, safety, convenience, decency or morals'. This legislative framework does not provide safeguards to all defendants who are mentally ill, as those held in custody under blasphemy laws do not have any such rights in law. Concerns have been voiced by human rights organisations and in the newspapers that a significant proportion of individuals who have a mental illness are being prosecuted under the blasphemy laws (Husain, 2014).

The Sindh Mental Health Ordinance 2013 has been endorsed by the Sindh Assembly (Government of Sindh, 2013). However the 'Rules and Regulations' and necessary 'Forms' which will ensure implementation in daily practice, although prepared and submitted to the government, have not yet been processed.

The Punjab government enacted the Punjab Mental Health Act in 2014, without significant consultation with mental health professionals or advocacy groups. The act itself is an amendment of the 2001 ordinance and merely substitutes the words 'Federal Government' with 'Government' as reported by the Law and Parliamentary Affairs Department (Government of Punjab, 2014).

The situation in the provinces of Balochistan and Khyber Pakhtunkhwa remains legally ambiguous. The Mental Health Ordinance Pakistan 2001 has lapsed, and there has been no new act from the provincial parliament to remedy this. This legal lacuna requires urgent remedy.

\section{Ongoing concerns}

Although attempts have been made to put laws and regulations into place, the biggest problem that psychiatrists in Pakistan face continues to be implementation (Mufti, 2010). There is no recognised or identified authority either in policing or law or social welfare which psychiatrists can approach in cases of emergency.

The same problem is faced by the relatives of patients. Where a patient is very disturbed or aggressive there is no identified agency to which relatives can turn for help or assistance. Currently, the family are the mainstay of support for people with mental disorders. There is a wide variation in access to services and treatment received for mental disorders, which anyway is generally perceived by the family as either ineffective or only partially effective (Tareen et al, 2008). Family members struggle to manage mental disorders and use physical containment as a method of treatment (Mirza et al, 2009). This makes those with mental 
disorders vulnerable to human rights abuses due to lack of appropriate safeguards.

Apart from the government hospitals, there are a large number of private in-patient facilities but these are not registered with the Social Welfare Agency or Health Directorate and so there is no check or monitoring of their performance or of the way that the patients are treated, which leads at times to patient abuse, as reported in the New Statesman (Shackle, 2008). The World Health Organization's AIMS report (2009) for Pakistan highlights that, regarding mental health activities in the criminal justice system, only a small proportion of prisons (1-20\%) have at least one prisoner per month in treatment contact with a mental health professional. As for training, a few (1-20\%) police officers and no judges and lawyers have participated in educational activities on mental health in the past 5 years. An appropriate legislative framework is required to improve the human rights situation of those with mental disorders, and this must be developed following consultation with all the stakeholders to ensure that, when implemented, it is effective in achieving its goals.

\section{Conclusion}

In recent times there have been efforts on the part of psychiatrists, other mental health professionals and voluntary sector organisations to create awareness among the general public of the need for proper treatment of patients with mental illness, about the rights of the patient, the responsibilities of the family and the overall responsibility of the government and society. There are also continued efforts to reduce the stigma of mental illness through articles in newspapers, the organisation of seminars and discussion groups and distribution of leaflets, to disseminate information and foster knowledge and understanding within the family and society. Malik \& Bokharey (2001) describe how institutional effort can translate into improvement of both the clinical and the human rights situations of those with mental disorders. The legislative framework is the linchpin that will support all of this work. It is hoped that the progress in Sindh will act as a stimulus to other provinces to take forward mental health legislation and work towards effective implementation in their respective areas. There is a need for stakeholders such as patients' advocacy groups, families and mental health professionals to join hands to exert political pressure so that an appropriate mental health legislative framework is in place for the population of Pakistan. Unfortunately, experience shows that drafting, approval and implementation of legislation is often subject to prolonged delays.

\section{References}

Gilani, A., Gilani, U., Kasi, P., et al (2005) Psychiatric health laws in Pakistan: from lunacy to mental health. PLoS Med, 2(11), e317.

Government of Pakistan (2001) Mental Health Ordinance. Government of Pakistan Printing Press. Available at http:// punjablaws.punjab.gov.pk/public/dr/MENTAL \% 20HEALTH \% 20 ORDINANCE \% 20FOR \% 20PAKISTAN \% 202001.doc.pdf (accessed April 2014)

Government of Punjab (2014) The Punjab Mental Health (Amendment) Act 2014. Law and Parliamentary Affairs. Available at http://punjablaws.punjab.gov.pk/public/dr/THE \% 20PUNJAB \% 20 MENTAL \% 20HEALTH \% 20(AMENDMENT) \% 20ACT \% 202014.doc. pdf (accessed April 2014).

Government of Sindh (2013) The Sindh Mental Health Ordinance 2013. Sindh Government Press. Available at http://www.pas.gov. pk/uploads/acts/Sindh\% 20Act \% 20No.L \% 20of \% 202013.pdf (accessed April 2014).

Husain, M. (2014) Blasphemy laws and mental illness in Pakistan. Psychiatric Bulletin, 38, 40-44.

Malik, S. \& Bokharey, I. (2001) Breaking the chains. Psychiatric Bulletin, 25, 273-275.

Mirza, I., Tareen, A., Davidson, L., et al (2009) Community management of intellectual disabilities in Pakistan: a mixed methods study. Journal of Intellectual Disability Research, 53, 559-570.

Mufti, K. (2010) Implementation of mental health policy in Pakistan. Journal of the Postgraduate Medical Institute, 24, 246

Pakistan Association for Mental Health (2002) Workshop Report on Mental Health Ordinance 2001. PAMH.

Rehman, A. (1994) Forensic psychiatry in Pakistan. In Current State of Psychiatry in Pakistan (eds I. Tareen, M. Chaudhry \& A. Javed), pp. 47-52. Pakistan Psychiatric Society.

Shackle, S. (2008) Pakistan's forgotten patients. New Statesman, 22 October. Available at http://www.newstatesman.com/humanrights/2008/10/mental-health-pakistan-rights (accessed April 2014).

Tareen, A., Mirza, I., Mujtaba, M., et al (2008) Primary care treatment for child and adolescent neuro-psychiatric conditions in remote rural Punjab, Pakistan - a cross-sectional survey. Child: Care, Health and Development, 34, 801-805.

World Health Organization (2009) Mental Health System in Pakistan: A Report of the Assessment of the Mental Health System in Pakistan Using the World Health Organization Assessment Instrument for Mental Health Systems. WHO. Available at http:// www.who.int/mental_health/pakistan_who_aims_report.pdf (accessed April 2014).

\section{BJPsych International's online presence}

Blog

http://www.bjpinternationalblog.org/

Facebook

https://www.facebook.com/BJPsychInternational

Twitter

@ BJPsychInt 